\title{
1 Three-dimensional analysis of $\beta$-cell proliferation by a novel mouse model
}

2

3 Shinsuke Tokumoto ${ }^{\mathrm{a}}$, Daisuke Yabe ${ }^{\mathrm{a}, \mathrm{b}}$, Hisato Tatsuoka ${ }^{\mathrm{a}}$, Ryota Usui ${ }^{\mathrm{a}}$, Muhammad Fauzi ${ }^{\mathrm{a}}$,

4 Ainur Botagarova ${ }^{\mathrm{a}}$, Hisanori Goto ${ }^{\mathrm{a}}$, Pedro Luis Herrera ${ }^{\mathrm{c}}$, Masahito Ogura ${ }^{\mathrm{a}}$, Nobuya Inagaki ${ }^{\mathrm{a}}{ }{ }$

5

$6 \quad{ }^{a}$ Department of Diabetes, Endocrinology and Nutrition, Graduate School of Medicine, Kyoto

7 University, 54 Kawara-cho, Shogoin, Sakyo-ku, Kyoto 606-8507, Japan

8

$9{ }^{b}$ Department of Diabetes and Endocrinology, Gifu University Graduate School of Medicine,

10 Gifu, Japan

11

$12{ }^{c}$ Department of Genetic Medicine and Development, University of Geneva Medical School,

13 Geneva, Switzerland.

14

15

16

17

18

19

20

21

22

23

24

*Corresponding author (Nobuya Inagaki). Tel.: +81-75-751-3560, fax: +81-75-771-6601, email: inagaki@kuhp.kyoto-u.ac.jp

(7)




\section{Summary}

26 Inducing $\beta$-cell proliferation could inhibit diabetes progression. Many factors have been

suggested as potential $\beta$-cell mitogens, but their impact on $\beta$-cell replication has not been

confirmed due to the lack of a standardized $\beta$-cell proliferation assay. In this study, we

developed a novel method that specifically labels replicating $\beta$ cells and yields more

reproducible results than current immunohistochemical assays. We established a mouse line

expressing the fluorescent ubiquitination-based cell cycle indicator (Fucci2a) reporter only in

$\beta$ cells through Cre-mediated recombination under the control of the rat insulin promoter

(RIP-Cre;Fucci2aR). Three-dimensional imaging of optically cleared pancreas tissue from

these mice enabled the quantification of replicating $\beta$ cells in islets and morphometric

revealed cell cycle progression of $\beta$ cells. Thus, this novel mouse line is a powerful tool for spatiotemporal analysis of $\beta$-cell proliferation in response to mitogen stimulation.

Introduction in pathophysiological states. Many factors have been reported as potential $\beta$-cell mitogens, although the $\beta$-cell mitogenic effect by one of them has not been reproducible (Gusarova et al., 2014). The inconsistent results can be explained by the lack of a standardized method for quantifying replicating $\beta$ cells (Cox et al., 2016). Thus far, determination of the $\beta$-cell proliferation rate has relied on immunohistochemical detection of cell cycle markers such as nucleotide analogs (5-bromo-2'-deoxyuridine [BrdU] and 5-ethynyl-2'-deoxyuridine [EdU]) or replication proteins (proliferating cell nuclear antigen and Ki-67). However, results

49 obtained by the immunohistochemical assays show inter-laboratory variability (Cox et al., 
50 2016) caused by methodological differences-e.g., in immunolabeling and image acquisition techniques. Replicating non- $\beta$ cells within islets may also confound immunohistochemical analyses. Furthermore, there are presently no alternative methods that can be used to resolve

53 these discrepant findings. Thus, new methods for quantifying replicating $\beta$ cells are required 54 in order to validate the effects of potential $\beta$-cell mitogens. relies on the expression of a pair of fluorescent proteins: mCherry-hCdt1(30/120) (a degron of chromatin licensing and DNA replication factor [Cdt]1 fused to a fluorescent protein in the red spectrum) and mVenus-hGem (1/110) (a degron of Geminin fused to a fluorescent protein in the green spectrum). Reciprocal expression of these paired proteins labels cells in $\mathrm{G}_{1}$ phase and those in $\mathrm{S} / \mathrm{G}_{2} / \mathrm{M}$ phase with red and green fluorescence, respectively. Thus, the Fucci system can be used to visualize the $\mathrm{G}_{1} / \mathrm{S}$ transition and quantify replicating cells. probe are labeled according to cell cycle phase. Using this model, we specifically evaluated $\beta$-cell proliferation induced by administration of the insulin receptor antagonist S961 (a reported $\beta$-cell mitogen [Jiao et al., 2014]). In addition, we performed three-dimensional (3D) analyses of whole islets by observing optically cleared pancreas of these mice and found a strong and significant correlation between islet size and the number of replicating $\beta$ cells per islet. These results demonstrate the utility of this mouse model for the study of $\beta$-cell proliferation.

\section{Results}


technology, which is a proven tool for detecting actively proliferating cells. The R26-

Fucci2aR transgenic mouse line harboring an upgraded Fucci2a reporter was recently generated in which Cre/loxP-mediated conditional expression of the Fucci2a transgene at the Rosa26 locus is driven by the cytomegalovirus early enhancer/chicken $\beta$ actin promoter (Mort et al., 2014). By crossing rat insulin promoter (RIP)-Cre (Herrera et al., 1998) and R26-Fucci2aR mice, we generated the RIP-Cre;Fucci2aR line in which the Fucci2a probe is specifically expressed in $\beta$ cells (Fig. 1A). RIP-Cre;Fucci2aR mice showed similar body weight and arbitrary blood glucose levels compared to Fucci2aR littermates (Fig. 1B and 1C), and there was no significant difference in blood glucose and insulin levels during in the oral glucose tolerance test ( $2 \mathrm{~g} / \mathrm{kg}$ ) between them (Fig. 1D and 1E), indicating that RIP-Cre; Fucci2aR mice have a normal metabolic profile.

\section{$\beta$ cell-specific Fucci expression in RIP-Cre;Fucci2aR mice}

As proof of principle, we investigated the expression pattern of the Fucci2a probe in RIP-Cre;Fucci2aR mice. In order to characterize not only mCherry $^{+}$but also mVenus $^{+}$cells, we induced $\beta$-cell proliferation in RIP-Cre;Fucci2aR mice by continuous infusion of the vehicle phosphate-buffered saline (PBS) or insulin receptor antagonist S961 over 7 days with an osmotic pump. At the end of the treatment, frozen sections were prepared from the dissected pancreas and immunostained for insulin, glucagon, somatostatin, and Nkx-6.1, and the fluorescent signals of the Fucci2a probe were directly observed. In S961-treated RIPCre;Fucci2aR mice, mCherry and mVenus were expressed specifically in insulin ${ }^{+}$and $\mathrm{Nkx}$ $6.1^{+}$cells (Figure 2A and 2D), but not in glucagon ${ }^{+}$or somatostatin $^{+}$cells (Figure $2 \mathrm{~B}$ and 2C). To ensure that replicating $\beta$ cells could be quantified, we compared the results of the EdU assay and the $\beta$-cell proliferation assay performed using RIP-Cre;Fucci2aR mice. Vehicle- and S961-treated mice were administered EdU $6 \mathrm{~h}$ before sacrifice, and mVenus ${ }^{+}$ 
100 cells (Figure 2E) or $\mathrm{EdU}^{+}$insulin ${ }^{+} \mathrm{DAPI}^{+}$cells (Figure $2 \mathrm{~F}$ ) were counted in frozen sections.

101 We found that the value of Venus $^{+}$cells per $\beta$ cells tended to be higher than that of EdU

102 insulin $^{+}$cells per $\beta$ cells.

103

\section{D Imaging of islets in RIP-Cre;Fucci2aR mice}

Since each islet is densely packed with various cell types, replicating $\beta$ cells can be

misidentified in histological sections labeled for insulin and replication markers. In order to

detect and quantify replicating $\beta$ cells in 3D in whole islets of RIP-Cre; Fucci2aR mice,

CUBIC clearing reagent (Kubota et al., 2017) was applied to pancreatic tissue samples from

vehicle- or S961-treated RIP-Cre;Fucci2aR mice, and 3D images of the optically cleared

tissue were obtained with a light sheet microscope equipped with a $5 \times$ objective lens. The

spatial distributions of $\mathrm{mVenus}^{+}$and $\mathrm{mCherry}^{+}$cells were simultaneously visualized (Figure

3A-3F; Movie S1). Islets contained more $\mathrm{mVenus}^{+}$cells following S961 treatment (Figure

$1133 \mathrm{C}$ and 3D). Spot objects corresponding to each $\mathrm{mVenus}^{+}$or $\mathrm{mCherry}^{+}$cells were

114 reconstructed using Imaris Spot Detection and quantified by an automated process to

119 Given the utility of the Fucci2a probe for real-time monitoring of the cell cycle, we 


\section{The number of replicating $\beta$ cells per islet is positively correlated with islet size}

The relationship between the number of replicating $\beta$ cells per islet and the

morphological characteristics of islets is unclear. We address this issue by analyzing 3D

images obtained from RIP-Cre;Fucci2aR mice. Blood glucose and insulin levels were higher

in mice treated with $\mathrm{S} 961(\mathrm{~N}=4)$ than in those treated with vehicle $(\mathrm{N}=4)$ (Figure 4A, 4B).

When we examined all islets whose $\beta$-cell cluster diameter was over $100 \mu \mathrm{m}$, the $\beta$-cell

cluster diameter and $\beta$-cell number per islet were greater in S961-treated RIP-Cre; Fucci2aR

mice (Figure 4C, 4D, 4E). In addition, the proportion of $\mathrm{mVenus}^{+}$cells per islet were higher in S961-treated as compared to control mice (Figure 4F). Moreover, the mVenus ${ }^{+}$cell

number per islet was positively correlated with $\beta$-cell number per islet in both vehicle-treated (Figure 4G; $\mathrm{r}=0.87, \mathrm{P}<0.0001$ ) and S961-treated (Figure 4G; $\mathrm{r}=0.84, \mathrm{P}<0.0001$ ) mice.

Next, we investigated whether this positive correlation could be also found under a physiological condition such as diet-induced obesity. The RIP-Cre;Fucci2aR mice were divided into two groups: one fed with high-fat diets (HFD) and the other fed with control diets for 13 weeks. HFD group $(\mathrm{N}=7)$ gained significantly more body weight than control diet group $(\mathrm{N}=7)$ at the end of 13-week feedings (Figure 5A). Compared to control diet group, HFD group revealed greater $\beta$-cell cluster diameter (Figure 5B, 5C), more $\beta$-cell number per islet (Figure 5D) and higher proportion of $\mathrm{mVenus}^{+}$cells per islet (Figure 5E). Finally, the positive correlation between $\mathrm{mVenus}^{+}$cell number per islet and $\beta$-cell number per islet was also found in both HFD group (Figure 5F; $\mathrm{r}=0.81, \mathrm{P}<0.0001$ ) and control diet group (Figure 5F; $r=0.60, P<0.0001$ ). These data indicate that the number of replicating $\beta$ cells per islet depends on the size of the islet.

\section{$\beta$-cell proliferation induced by $S 961$ is not due to hyperglycemia}

Hyperglycemia has been shown to induce $\beta$-cell proliferation (Alonso et al., 2007; 
150 Porat et al., 2011). Since S961 administration causes hyperglycemia, we investigated whether

151 this mediates $\beta$-cell proliferation during S961 treatment. To exclude the effects of

152 hyperglycemia, we normalized blood glucose levels in S961-treated RIP-Cre;Fucci2aR mice

153 by co-administration of sodium-glucose cotransporter 2 inhibitor (SGLT2i). The mice were

154 divided into four groups: vehicle treatment with control diet (vehicle + control), vehicle

155 treatment with control diet containing $0.02 \%$ empagliflozin (vehicle $+0.02 \%$ empagliflozin),

156 S961 treatment with control diet (S961 + control), and S961 treatment with control diet containing $0.02 \%$ empagliflozin (S961 + 0.02\% empagliflozin). Although blood glucose level was higher in the S961 + control than in the S961 + 0.02\% empagliflozin group, the level in the latter was similar to that in the vehicle + control group (Figure 6A). The S961+0.02\% empagliflozin group had a lower insulin level than the S961 + control group but nonetheless showed hyperinsulinemia (Figure 6B), reflecting the continuous pharmacological action of S961 irrespective of empagliflozin co-administration.

We next investigated the morphological characteristics of islets in all four groups and found that islets were larger in mice treated with S961 as compared to vehicle (Figure 6C, $6 \mathrm{D}, 6 \mathrm{E}) . \beta$-cell cluster diameter was larger in the vehicle + control as compared to the vehicle $+0.02 \%$ empagliflozin group, while no difference was observed between S961 + control and S961 + 0.02\% empagliflozin groups (Figure 6C, 6D). On the other hand, while the number of

$168 \beta$ cells per islet was greater in S961 + 0.02\% empagliflozin group as compared to S961 + 169 control group (Figure 6E), there was no difference in the proportion of VVenus $^{+}$cells number 170 per islet between the two groups (Figure 6F). In all four groups, there were positive correlations between mVenus $^{+}$cell number and $\beta$-cell number per islet (vehicle + control: $r=$ 0.78, $\mathrm{P}<0.0001 ;$ vehicle $+0.02 \%$ empagliflozin diet: $\mathrm{r}=0.74, \mathrm{P}<0.0001 ; \mathrm{S} 961+$ control

173 diet: $\mathrm{r}=0.92, \mathrm{P}<0.0001$; and $\mathrm{S} 961+0.02 \%$ empagliflozin diet: $\mathrm{r}=0.90, \mathrm{P}<0.0001$; Figure

$1746 \mathrm{G})$. These results indicate that hyperglycemia does not mediate S961-induced $\beta$-cell 
replication.

\section{Discussion}

Identifying potential $\beta$-cell mitogens could lead to a novel diabetes therapy. Although

many factors that control $\beta$-cell replication have been identified to date, their mitogenic

effects on $\beta$ cells have not been precisely evaluated since immunohistochemical assays are

unreliable for accurately identifying $\beta$ cells. A recent study reported inter-laboratory

variability in the immunohistochemical detection of Ki-67 for the identification of $\beta$ cells and

quantification of their replication; the authors concluded that the discrepancy among

laboratories was due to the misidentification of replicating non- $\beta$ cells within islets as $\beta$ cells

(Cox et al., 2016). Since many different cell types are densely packed in sphere-like islets, the analysis of 2D immunohistochemical data could account for inaccuracies in the detection of $\beta$

cells. Furthermore, the nucleotide analog BrdU, which is often used as a cell cycle marker in

traditional immunohistochemical assays, has unfavorable effects on the cell cycle of $\beta$ cells

(de Casteele et al., 2013). Thus, immunohistochemistry using cell cycle markers such as Kiquantify replicating $\beta$ cells.

Fucci2a, a single fluorescence marker for monitoring cell cycle transition,

199 EdU labeling assay, which cannot detect $\beta$ cells in $\mathrm{G}_{2} / \mathrm{M}$ phase. 
$201 \beta$ cells, and increases the sample size compared to 2D immunohistochemical assays. We

optically cleared pancreas tissue samples from RIP-Cre/Fucci2aR mice for 3D fluorescence

analysis allowed us to examine the correlation between $\beta$-cell proliferative capacity and the

morphological characteristics of each islet. Furthermore, intravital imaging demonstrated that

longitudinal spatiotemporal data on $\beta$-cell proliferation can be obtained from RIP-

Cre/Fucci2aR mice. The 3D analysis of the pancreas of RIP-Cre/Fucci2aR mice revealed a

higher $\beta$-cell proliferation rate within each islet in mice treated with S961 than in those with previous reports on S961-induced $\beta$ cell proliferation and mass expansion (Jiao et al., 2014). In addition, the strong positive correlation between $\mathrm{mVenus}^{+}$cell and total $\beta$-cell number per islet suggested that larger islets contain more replicating $\beta$ cells.

The signals that regulate $\beta$-cell proliferation upon S961 treatment are not known. showed that S961-induced hyperinsulinemia and $\beta$ cell mass expansion occurred even when blood glucose levels were normalized by co-administration of a monoclonal glucagon receptor antibody (Okamoto et al., 2017). Our results showed that S961 stimulated $\beta$-cell proliferation and increased $\beta$-cell number per islet even when hyperglycemia was normalized by SGLT2i treatment. These results provide new evidence for the existence of mitogenic factors mediating S961-induced $\beta$-cell proliferation, except under hyperglycemic conditions. mice. Therefore, mitogenic effects on non- $\beta$ cells must be investigated using other methods. 
225 Secondly, the attenuation of fluorescence by light scattering limited the observation depth

226 from the pancreas surface. Such signal attenuation is unavoidable despite the optical clearing

227 process. Under the light sheet microscope, only islets near ( 2.0 $\mathrm{mm}$ from $)$ the surface were

228 clearly detected for quantification of fluorescent cells. Although this restricts the size of the

229 islet population, the sample size is still larger using our method as compared to a

230 conventional immunohistochemical assay because it is based on 3D analysis of the whole

231 pancreas.

232 In summary, the transgenic mouse line expressing the Fucci2a probe in $\beta$ cells

233 developed in this study provides a new tool for analyzing $\beta$-cell proliferation in a more

234 reliable and reproducible manner than conventional immunohistochemistry. The high spatial

235 resolution of the 3D images obtained with a light-sheet microscope allows accurate detection

236 of replicating $\beta$-cells. This system can be useful for validating the efficacy and therapeutic

237 potential of $\beta$-cell mitogens for inhibition of diabetes progression.

239 Acknowledgments

240 The authors thank Asako Sakaue-Sawano and Atsushi Miyawaki for their scientific

241 discussion; Saki Kanda and Sara Yasui for technical assistance; and Yukiko Inokuchi,

242 Yukiko Tanaka, and Fumiko Uwamori for secretarial assistance. This work was supported by

243 Kyoto University Live Imaging Center and in part by Grants-in-Aid KAKENHI 16H06280

244 "ABiS".

246 Author Contributions

247 The study was designed by S.T., D.Y., and N.I. Experiments were performed by S.T. and

248 A.B., and data were analyzed by S.T. The manuscript was written by S.T., D.Y., and N.I.

249 with input from all authors. 


\section{Declaration of Interests}

252 S. Tokumoto reports no conflict of interests relevant to this study. D. Yabe received

253 consulting or speaking fees from MSD K.K., Nippon Boehringer Ingelheim Co. Ltd., and

254 Novo Nordisk Pharma Ltd. D. Yabe also received clinically commissioned/joint research

255 grants from Taisho Toyama Pharmaceutical Co. Ltd., MSD K.K., Ono Pharmaceutical Co.

256 Ltd., Novo Nordisk Pharma Ltd., Arklay Co. Ltd., Terumo Co. Ltd., and Takeda

257 Pharmaceutical Co. Ltd. N. Inagaki received clinical commissioned/joint research grants from

258 Mitsubishi Tanabe, AstraZeneca, Astellas, and Novartis Pharma and scholarship grants

259 from Takeda, MSD, Ono, Sanofi, Japan Tobacco Inc., Mitsubishi Tanabe, Novartis,

260 Boehringer Ingelheim, Kyowa Kirin, Astellas, and Daiichi-Sankyo.

261

262

\section{Figure legends}

Figure 1. Genotype and metabolic phenotype of RIP-Cre;Fucci2aR mice. (A) Breeding scheme for the generation of RIP-Cre;Fucci2aR mice. RIP-Cre and Fucci2aR mouse lines were crossed to obtain RIP-Cre;Fucci2aR mice. After Cre-mediated recombination, the Fucci2a transgene was expressed specifically in $\beta$ cells. (B) Body weight and (C) arbitrary blood glucose levels of RIP-Cre;Fucci2aR $(\mathrm{N}=7)$ and Fucci2aR control $(\mathrm{N}=7)$ mice during postnatal growth. (D, E) Oral glucose tolerance test ( $2 \mathrm{~g} / \mathrm{kg}$ body weight) was performed on RIP-Cre; Fucci2aR $(\mathrm{N}=7)$ and Fucci2aR control $(\mathrm{N}=7)$ mice at 8 weeks. Data are expressed as mean \pm SEM. $* \mathrm{P}<0.05$ (Mann-Whitney $\mathrm{U}$ test).

Figure 2. $\beta$ Cell-specific expression of Fucci2a in RIP-Cre;Fucci2aR mice. (A-D) Frozen 
274 sections of pancreas tissue from RIP-Cre;Fucci2aR mice treated with S961 at 8 weeks of age

275 immunostained for islet hormones and Nkx 6.1. Representative fluorescence images of

$276 \mathrm{mCherry}^{+}$(red) and $\mathrm{mVenus}^{+}$(yellow) cells and immunofluorescence for islet hormones

277 (green): insulin (A), glucagon (B), and somatostatin (C). (D) All mCherry ${ }^{+}$(red) and

278 mVenus $^{+}$(green) cells were Nkx 6.1-positive (yellow). Nuclei were stained with DAPI

279 (blue). Scale bar, $100 \mu \mathrm{m}$. (E) Quantification of $\mathrm{mVenus}^{+}$cells in the islets of RIP-

280 Cre;Fucci2aR mice treated with vehicle (PBS; $\mathrm{N}=4)$ or $\mathrm{S} 961(10 \mathrm{nM} /$ week; $\mathrm{N}=4) . * \mathrm{P}<$

0.05. (F) Quantification of EdU ${ }^{+} \beta$ cells in islets of RIP-Cre;Fucci2aR mice treated with

vehicle (PBS; $\mathrm{N}=4)$ or $\mathrm{S} 961(10 \mathrm{nM} /$ week; $\mathrm{N}=4) .{ }^{*} \mathrm{P}<0.05$. Data are expressed as mean \pm

SEM.

Figure 3. 3D Imaging of islets in vehicle- and S961-treated RIP-Cre;Fucci2aR mice.

286 Representative 3D images of islets following treatment for 1 week with vehicle or S961. (A,

B) Representative fluorescence images of $\mathrm{mCherry}^{+}$(red) and (C, D) $\mathrm{mVenus}^{+}$(green) cells.

$(\mathrm{G}, \mathrm{H})$ Morphological 3D reconstruction of $\mathrm{mCherry}^{+}$(red) and $\mathrm{mVenus}^{+}$(green) cells for $\mu \mathrm{m}$.

Figure 4. Quantification of replicating $\beta$ cells in RIP-Cre;Fucci2aR mice following S961

\section{treatment.}

(A, B) RIP-Cre;Fucci2aR mice were treated with S961 (10 nM/week; N = 4) or vehicle (PBS;

$\mathrm{N}=4$ ) for 7 days. (A) Arbitrary blood glucose and (B) serum insulin levels at the end of the 
299 mice). (D) $\beta$-cell cluster diameter in S961- and vehicle-treated mice. ****P $<0.0001(\mathrm{~N}=4)$.

300 (E) Number of $\beta$ cells per islet in S961- or vehicle-treated mice. $* \mathrm{P}<0.05(\mathrm{~N}=4)$. (F)

301 Percentage of mVenus $^{+}$cells per islet in S961- and vehicle-treated mice. $* * * * \mathrm{P}<0.0001(\mathrm{~N}$

$302=4)$. (G) Correlation between number of $\mathrm{mVenus}^{+}$cells and number of $\beta$ cells per islet.

303 mVenus $^{+}$cell number and $\beta$ cell number per islet was strongly correlated in both groups

$304(\mathrm{~S} 961, \mathrm{r}=0.87, \mathrm{P}<0.0001$; vehicle, $\mathrm{r}=0.77, \mathrm{P}<0.0001)$. Data are presented as mean \pm 305 SEM.

Figure 5. Quantification of replicating $\beta$ cells in RIP-Cre;Fucci2aR mice following

309 (A) Body weight of RIP-Cre;Fucci2aR mice fed with high-fat diets (HFD; N =7) or control

310 diets (Control; $\mathrm{N}=7$ ) for 13 weeks. (B) Histogram of $\beta$-cell cluster diameter in RIP-

311 Cre;Fucci2aR mice under HFD or control diet feeding. Morphometric analysis was

312 performed on islets harboring $\beta$-cell clusters with a diameter $>100 \mu \mathrm{m}(\mathrm{HFD}, \mathrm{n}=407$ islets,

$313 \mathrm{~N}=4$ mice; Control, $\mathrm{n}=432$ islets, $\mathrm{N}=4$ mice). (C) $\beta$-cell cluster diameter. $* * * * \mathrm{P}<0.0001$

$314(\mathrm{~N}=4)$. (D) Number of $\beta$ cells per islet. $* * * * \mathrm{P}<0.0001(\mathrm{~N}=4)$. (E) Percentage of mVenus ${ }^{+}$

315 cells per islet. $* * * * \mathrm{P}<0.0001(\mathrm{~N}=4)$. (F) Correlation between number of $\mathrm{mVenus}^{+}$cells and

316 number of $\beta$ cells per islet. mVenus $^{+}$cell number and $\beta$ cell number per islet was strongly

317 correlated in both groups (HFD, $\mathrm{r}=0.81, \mathrm{P}<0.0001$; Control, $\mathrm{r}=0.60, \mathrm{P}<0.0001)$. Data are

318 presented as mean \pm SEM.

Figure 6. S961-induced $\beta$ cell proliferation is not mediated by hyperglycemia.

321 (A, B) RIP-Cre;Fucci2aR mice were divided into four groups: 1) vehicle + control, treated

322 with vehicle and fed a control $\operatorname{diet}(\mathrm{N}=6) ; 2)$ vehicle $+0.02 \%$ empagliflozin, treated with 
323 vehicle and fed a diet supplemented with $0.02 \%$ empagliflozin $(\mathrm{N}=6) ; 3) \mathrm{S} 961+$ control,

324 treated with $\mathrm{S} 961(10 \mathrm{nM} /$ week $)$ and fed a control diet $(\mathrm{N}=6)$; and 4) S961 + 0.02\%

325 empagliflozin, treated with S961 (10 nM/week) and fed a diet supplemented with $0.02 \%$

326 empagliflozin $(\mathrm{N}=6)$. (A) Arbitrary blood glucose levels. $* \mathrm{P}<0.05, \mathrm{~S} 961+$ control diet

327 group vs. S961 + 0.02\% empagliflozin group. ${ }^{\dagger} \mathrm{P}<0.05, \mathrm{~S} 961+0.02 \%$ empagliflozin group

328 vs. Vehicle + control group. ${ }^{\ddagger} \mathrm{P}<0.05$, vehicle + control group vs. vehicle $+0.02 \%$

329 empagliflozin group. (B) Serum insulin levels at the end of the 7-day treatment. $* \mathrm{P}<0.05$,

330 S961 + control group vs. S961 + 0.02\% empagliflozin group. (C) Histogram of $\beta$-cell cluster

331 diameter. Morphometric analysis was performed on islets harboring $\beta$-cell clusters with a

332 diameter $>100 \mu \mathrm{m}$ (vehicle + control, $\mathrm{N}=4$ mice, $\mathrm{n}=496$ islets; vehicle $+0.02 \%$

333 empagliflozin, $\mathrm{N}=4$ mice, $\mathrm{n}=440$ islets; $\mathrm{S} 961+$ control, $\mathrm{N}=4$ mice, $\mathrm{n}=544$ islets; $\mathrm{S} 961+$

$3340.02 \%$ empagliflozin, $\mathrm{N}=4$ mice, $\mathrm{n}=391$ islets). (D) $\beta$-cell cluster diameter, (E) number of $\beta$

335 cells per islet, and $(\mathrm{F})$ percentage of $\mathrm{mVenus}^{+}$cells per islet. $* * \mathrm{P}<0.01(\mathrm{~N}=4), * * * \mathrm{P}<$

$3360.001(\mathrm{~N}=4), * * * * \mathrm{P}<0.0001(\mathrm{~N}=4)$; ns, not significant. $(\mathrm{G})$ Correlation between number

337 of mVenus $^{+}$cells and number of $\beta$ cells per islet. Venus $^{+}$cell and $\beta$-cell number per islet

338 were strongly correlated in all groups (vehicle + control, $\mathrm{r}=0.70, \mathrm{P}<0.0001$; vehicle +

$3390.02 \%$ empagliflozin diet, $\mathrm{r}=0.61, \mathrm{P}<0.0001 ; \mathrm{S} 961+$ control diet, $\mathrm{r}=0.93, \mathrm{P}<0.0001$; and

$340 \mathrm{~S} 961+0.02 \%$ empagliflozin diet, $\mathrm{r}=0.88, \mathrm{P}<0.0001) . \mathrm{V}+\mathrm{C}$, vehicle + control; $\mathrm{V}+\mathrm{E}$,

341 vehicle $+0.02 \%$ empagliflozin diet; S + C, S961 + control diet; S + E, S961 + 0.02\%

342 empagliflozin diet. Data are presented as mean \pm SEM. 


\section{STAR Methods}

\section{CONTACT FOR REAGENT AND RESOURCE SHARING}

346 Further information and requests for resources and reagents should be directed to and will be

347 fulfilled by the Lead Contact, Nobuya Inagaki (inagaki@kuhp.kyoto-u.ac.jp). RIP-Cre mice

348 were obtained under Material Transfer Agreements from Prof. Pedro L. Herrera. Fucci2aR

349 mouse strain (RBRC06511) was provided by RIKEN BRC through the National BioResource

350 Project of the MEXT/AMED, Japan.

\section{EXPERIMENTAL MODEL AND SUBJECT DETAILS}

\section{Generation of the transgenic mouse line}

354 To establish the mouse model for studying $\beta$-cell proliferation, we used mice harboring R26-

355 Fucci2aR (RIKEN BRC through Kyoto University Medical Science and Business Liaison

356 Organization). This newer Fucci2a reporter is a bicistronic Cre-inducible probe consisting of two fluorescent proteins: truncated Cdt1 (30/120) fused to mCherry, and truncated Geminin (1/110) fused to mVenus. The two fusion proteins are always alternately expressed according to cell cycle phase in the same ratio, making it possible to detect and quantify the number of labeled cells. By crossing Rip-Cre and Fucci2aR mice, we generated RIP-Cre;Fucci2aR mice expressing the Fucci2a reporter in a $\beta$ cell-specific manner. In these RIP-Cre;Fucci2aR mice, mCherry-hCdt1 (30/120) (red fluorescence) and mVenus-hGem (1/110) (green fluorescence) are expressed in $\beta$ cell nuclei during G0/G1 and S/G2/M phases, respectively. Only hemizygous males on the C57BL/6 background were used in this study. Mice had free access to standard rodent chow and water and were housed in a temperature-controlled environment under a 14:10-h light/dark cycle. Animal care and protocols were reviewed and approved by 


\section{METHOD DETAILS}

In vivo mouse studies

372 S961 was obtained from Novo Nordisk (Bagsværd, Denmark). Vehicle (PBS) or $10 \mathrm{nmol}$

373 S961 was loaded into an osmotic pump (Alzet 2001; DURECT Corp., Cupertino, CA, USA)

374 subcutaneously implanted into the back of RIP-Cre;Fucci2aR mice at 8 weeks of age. Mice

375 were euthanized and the pancreas was harvested 7 days after S961 or vehicle treatment.

376 Blood glucose levels were measured daily. Plasma was collected on days 0 and 7 to measure

377 insulin level. For a model of diet-induced obesity, six-week old RIP-Cre;Fucci2aR mice were

378 fed with high-fat diets (Research Diet, cat. no. D12492) or control diets (Research Diet, cat.

379 no. D12450J) for 13 weeks, and body weight were measured weekly. For the EdU labeling

380 assay, mice were intraperitoneally injected with EdU $(50 \mathrm{mg} / \mathrm{kg}) 6 \mathrm{~h}$ before sacrifice.

381

\section{Oral glucose tolerance test}

Mice were fasted for $16 \mathrm{~h}$ and then orally administered a $20 \%$ glucose solution $(2 \mathrm{~g} / \mathrm{kg}$ body weight). Blood samples were collected from the tail vein of mice 0,15 , and 30 min after glucose loading using heparinized calibrated glass capillary tubes (cat. no. 2-000-044-H;

Drummond Scientific Co., Broomall, PA, USA). Blood glucose level was measured using the Glutest Neo Sensor (Sanwa Kagaku Kenkyusho, Nagoya, Japan). Plasma samples were prepared by centrifuging the blood samples at $9000 \times g$ for $10 \mathrm{~min}$, and insulin level was measured using the Ultra Sensitive PLUS Mouse Insulin ELISA kit (cat. no. 49170-53; Morinaga, Tokyo, Japan).

\section{Immunohistochemical observation of tissue sections}

Mice were anesthetized by intraperitoneal injection of pentobarbital sodium $(10 \mathrm{mg} / \mathrm{kg})$; a 26- 
394 gauge needle was inserted into the left ventricle through the apex, and the mice were

395 transcardially perfused with cold PBS followed by cold 4\% paraformaldehyde (PFA, Wako

396 Pure Chemical Industries, Osaka, Japan). The harvested pancreas was immediately immersed

397 in PFA at $4^{\circ} \mathrm{C}$ with gentle shaking for less than $24 \mathrm{~h}$, and then embedded in Optimal Cutting

398 Temperature compound. Frozen samples were cut into 8- $\mu \mathrm{m}$ sections. After air drying, the

399 frozen sections were incubated with blocking buffer composed of PBS with $10 \%$ (v/v) goat

400 serum and $0.2 \%(\mathrm{v} / \mathrm{v})$ Triton-X100) for $30 \mathrm{~min}$ at room temperature, and then incubated

401 overnight at room temperature in blocking buffer supplemented with rabbit anti-insulin (200-

402 fold dilution; cat. no. ab181547), mouse anti-glucagon (2000-fold dilution; cat. no. ab10988),

403 rat anti-somatostatin (100-fold dilution; cat. no. ab30788), or rabbit anti-Nkx 6.1 (100-fold

404 dilution; cat. no. ab221549) antibody (all from Abcam, Cambridge, MA, USA), followed by

405 Alexa Fluor 647-conjugated goat anti-rabbit IgG (H+L) (200-fold dilution; cat. no. A-21245;

406 Thermo Fisher Scientific, Waltham, MA, USA), Alexa Fluor 647-conjugated goat anti-mouse

407 IgG (H+L) (200-fold dilution; cat. no. ab150115; Abcam), or Alexa Fluor 647-conjugated

408 goat anti-rat $\operatorname{IgG}(\mathrm{H}+\mathrm{L})$ (200-fold dilution; cat. no. ab150159; Abcam) for $1 \mathrm{~h}$ at room

409 temperature. The sections were incubated in PBS containing DAPI (final concentration: 0.01

$410 \mathrm{mg} / \mathrm{ml}$ ) for $15 \mathrm{~min}$ at room temperature and mounted with Vectashield (Vector Laboratories,

411 Burlingame, CA, USA) on $24 \times 40$-mm coverslips (cat. no. C024401; Matsunami Glass,

412 Osaka, Japan). Immunolabeled tissue sections were observed with an inverted fluorescence

413 microscope (BZ-X710; Keyence, Osaka, Japan). EdU was detected using the Click-iT EdU

414 Alexa Fluor 647 kit (Thermo Fisher Scientific) according to the manufacturer's protocol.

416 Tissue clearing

417 Pancreas tissue samples were collected and fixed as described above, washed three times for 418 more than $2 \mathrm{~h}$ each time in PBS at room temperature with gentle shaking. For delipidation 
and permeabilization, the samples were immersed in 50\% (v/v) CUBIC-L clearing reagent

420 for at least $6 \mathrm{~h}$ followed by CUBIC-L at $37^{\circ} \mathrm{C}$ with gentle shaking for 3 days. The CUBIC-L

421 reagent was refreshed daily during this period. After clearing, samples were immersed in

$42250 \%(\mathrm{v} / \mathrm{v})$ CUBIC-R for at least $6 \mathrm{~h}$ and in CUBIC-R at room temperature with gentle

423 shaking for at least 2 days.

424

425

$3 D$ Imaging

3D Images of optically cleared pancreas tissue were acquired with a light-sheet microscope

427 (Lightsheet Z.1; Carl Zeiss, Oberkochen, Germany) equipped with a 5×/0.16 NA objective

428 lens. For mCherry-hCdt1 (30/120) imaging, we used 22\% laser power (561-nm laser) and a

429 28-ms exposure time. For mVenus-hGem (1/110) imaging, we used 90\% laser power (488-

$430 \mathrm{~nm}$ laser) and a 70-ms exposure time. The z-stack images $(1920 \times 1920$ pixel, 16-bit $)$ were

431 acquired at $4.63 \mu \mathrm{m}$ intervals.

Intravital imaging

434 Following S961 treatment for 40 h, RIP-Cre;Fucci2aR mice were anesthetized by $1.5 \%-2 \%$

435 isoflurane (Wako Pure Chemical Industries) inhalation. The hair on the abdominal area was

436 removed and skin disinfected with $70 \%$ ethanol. A small oblique incision running parallel to

437 the last left rib was made to expose the pancreas on the left side of the abdominal wall. The

438 mice then were placed in the supine position on an electric heating pad maintained at $37^{\circ} \mathrm{C}$.

439 The pancreas was immobilized using a suction imaging device (Figure S1), and time-lapse

440 imaging was performed with a two-photon excitation microscope (FV1200MPE-BX61WI;

441 Olympus, Tokyo, Japan) equipped with a 25×/1.05 NA water-immersion objective lens

442 (XLPLN 25XWMP; Olympus) and an In-Sight DeepSee Ultrafast laser (Spectra Physics,

443 Santa Clara, CA, USA). Images were acquired every $5 \mathrm{~min}$ for $\sim 10 \mathrm{~h}$ in $5-\mu \mathrm{m}$ steps at a scan 
444 speed of $20 \mu$ s/pixel. Mice were euthanized after imaging.

446 Image processing

447 Acquired images were analyzed with the 3D reconstruction software Imaris (Bitplane AG,

448 Zurich, Switzerland). A whole series of consecutive 2D cross-sectional images was

449 reconstructed into a 3D structure using the "Volume rendering" function. Each islet was then

450 isolated using the "Crop 3D function”, and a Gaussian filter was applied for background

451 noise reduction. A spot detection algorithm was used for automated cell identification and

452 cell counts. Morphometric measurements of maximum diameter of $\beta$ cells within each islet

453 were obtained using the Imaris surface creation tool.

\section{Quantification and statistical analysis}

456 The Mann-Whitney U test was performed to evaluate the difference between two sets of data.

457 P values $<0.05$ were considered statistically significant. No statistical method was used to

458 predetermine sample size. Statistical analyses were performed using GraphPad Prism

459 (GraphPad Software, La Jolla, CA, USA).

\section{Supplemental Information}

462 Figure S1. Experimental setup of intravital pancreas imaging by two-photon microscopy, 463 Related to STAR Methods section.

Movie S1. 3D Imaging of Islets in RIP-Cre;Fucci2aR mice, Related to Figure 3

466 The movie shows how 3D images of islets were edited and analyzed using Imaris software.

468 Movie S2. In vivo imaging of an islet in a RIP-Cre;Fucci2aR mouse, Related to Figure 3 
469 The movie shows the G1-S transitions in two $\beta$ cells, which are also automatically detected

470 using the cell-tracking tool in Imaris. Scale bars, $50 \mu \mathrm{m}$. Time is shown in hours:minutes.

\section{References}

473 Alonso, L.C., Yokoe, T., Zhang, P., Scott, D.K., Kim, S.K., O’Donnell, C.P., and Garcia-

474 Ocaña, A. (2007). Glucose infusion in mice: a new model to induce beta-cell replication.

$475 \quad$ Diabetes 56, 1792-1801.

476 Cox, A. R., Barrandon, O., Cai, E.P., Rios, J.S., Chavez, J., Bonnyman, C.W., Lam, C.J., Yi, PLoS One 11, e0159276.

de Casteele, M.V., Cai, Y., Leuckx, G., and Heimberg, H. (2013). Mouse beta cell proliferation is inhibited by thymidine analogue labelling. Diabetologia 56, 2647-2650.

Gusarova, V., Alexa, C.A., Na, E., Stevis, P.E., Xin, Y., Bonner-Weir, S., Cohen, J.C., Hobbs, H.H., Murphy, A.J., Yancopoulos, G.D., and Gromada, J. (2014). ANGPTL8/betatrophin does not control pancreatic beta cell expansion. Cell 159, 691and Ueda, H.R. (2017). Whole-body profiling of cancer metastasis with single-cell resolution. Cell Rep. 20, 236-250. 
494 Mort, R.L., Ford, M.J., Sakaue-Sawano, A., Lindstrom, N.O., Casadio, A., Douglas, A.T.,

495 Keighren, M.A., Hohenstein, P., Miyawaki, A., and Jackson, I.J. (2014). Fucci2a: A

496 bicistronic cell cycle reporter that allows Cre mediated tissue specific expression in

$497 \quad$ mice. Cell Cycle 13, 2681-2696.

498 Okamoto, H., Cavino, K., Na, E., Krumm, E., Kim, S.Y., Cheng, X., Murphy, A.J.,

499 Yancopoulos, G.D., and Gromada, J. (2017). Glucagon receptor inhibition normalizes

$500 \quad$ blood glucose in severe insulin-resistant mice. Proc. Natl. Acad. Sci. U S A 114, 2753-

$501 \quad 2758$.

502 Porat, S., Weinberg-Corem, N., Tornovsky-Babaey, S., Schyr-Ben-Haroush, R., Hija, A.,

503 Stolovich-Rain, M., Dadon, D., Granot, Z., Ben-Hur, V., White, P., Girard, C.A., Karni,

504 R., Kaestner, K.H., Ashcroft, F.M., Magnuson, M.A., Saada, A., Grimsby, J., Glaser, B., 505 and Dor, Y. (2011). Control of pancreatic beta cell regeneration by glucose metabolism.

$506 \quad$ Cell Metabol. 13, 440-449.

507 Sakaue-Sawano, A., Kurokawa, H., Morimura, T., Hanyu, A., Hama, H., Osawa, H., 508 Kashiwagi, S., Fukami, K., Miyata, T., Miyoshi, H., Imamura, T., Ogawa, M., Masai, H., 509 and Miyawaki, A. (2008). Visualizing spatiotemporal dynamics of multicellular cell$510 \quad$ cycle progression. Cell 132, 487-498. 
Figure 1 bigaxiv prep(znteql: certified by peer revjey) bis the author/funder, who has granted bioRxiv a license to display the pFepioctia (RlP-Cre) aCC-BY-NC-ND 4.0 International license.
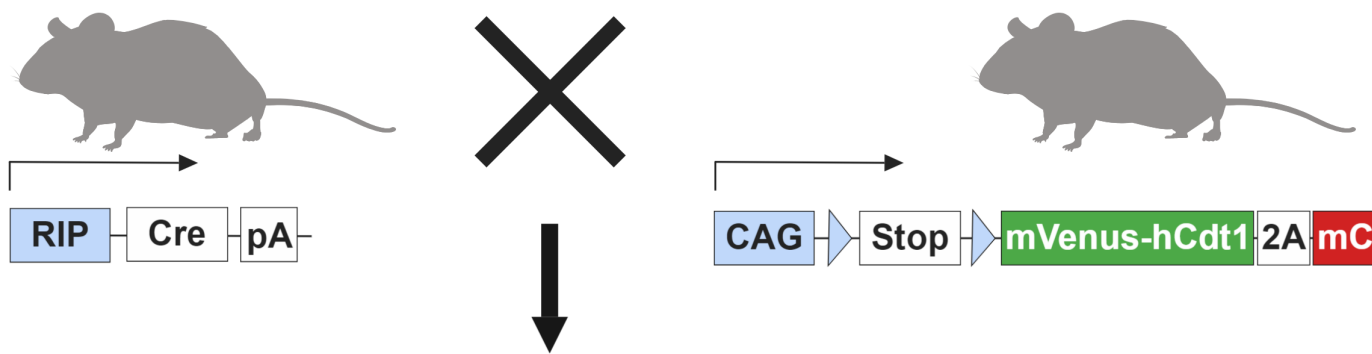

RIP-Cre;Fucci2aR

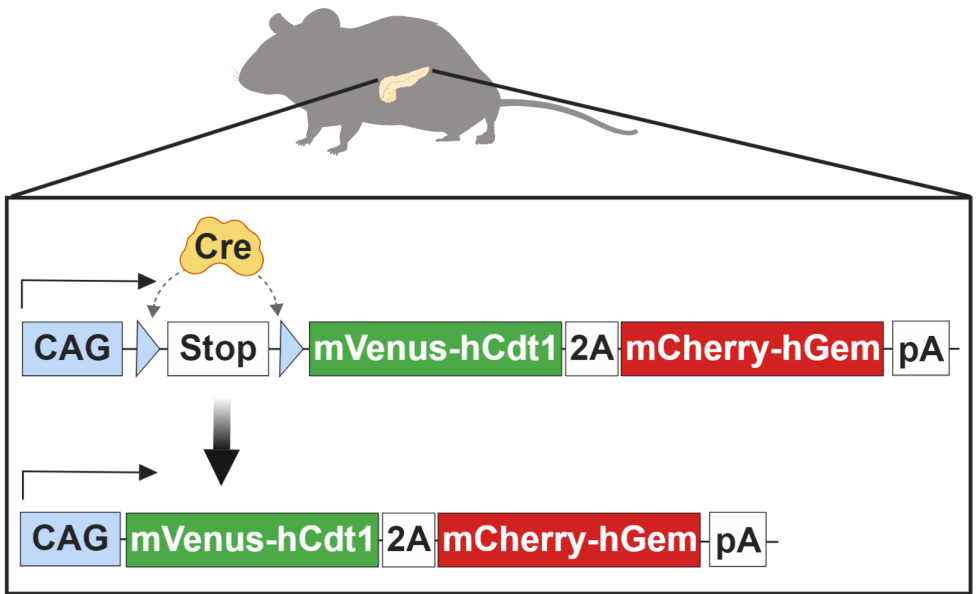

B
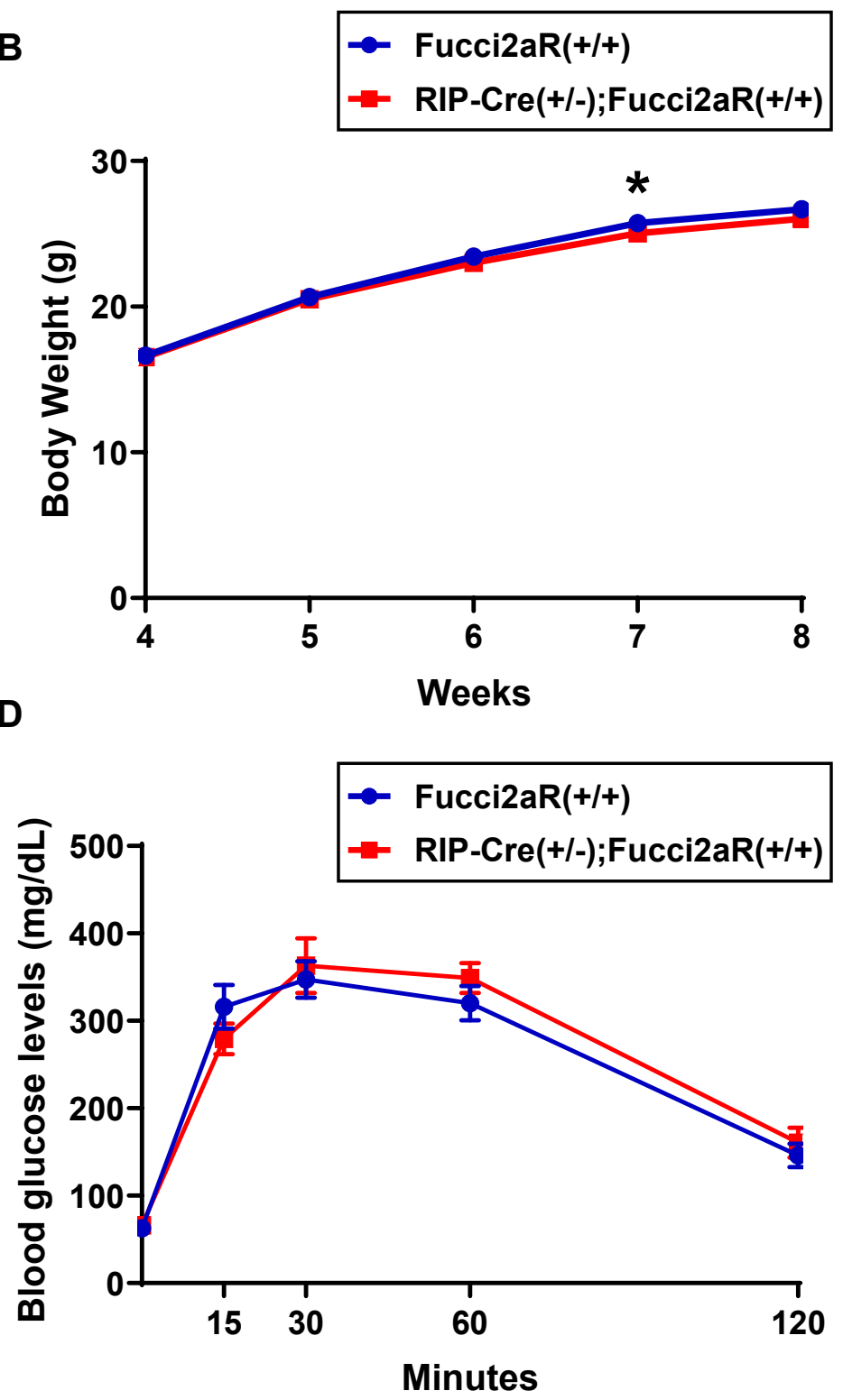

C

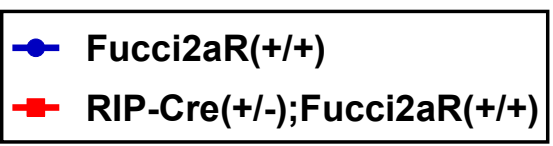

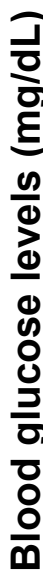

E
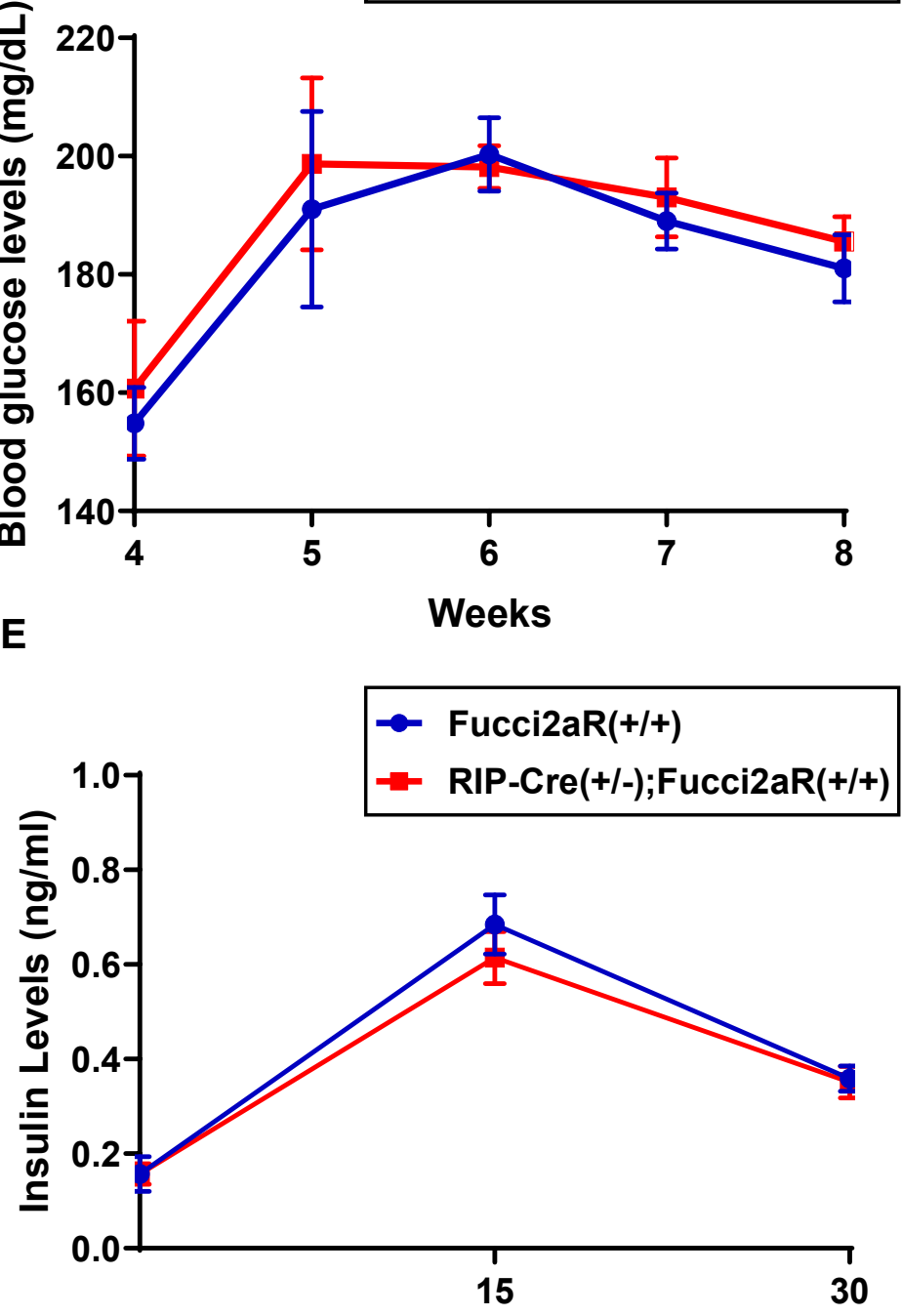

Minutes 
Figure 2 bioRxiv preprint doi: https://doi.org/10.1101/659904; this version posted June 4, 2019. The copyright holder for this preprint (which was not A certified by peer review) is the author/funder, who has granted bioRxiv a license to display the preprint in perpetuity. It is made available under aCC-BY-NC-ND 4.0 International license.

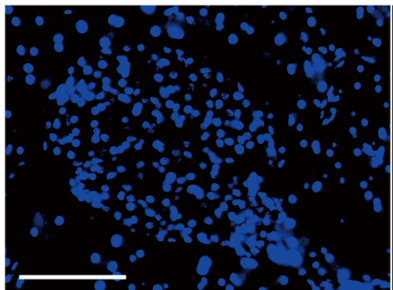

DAPI

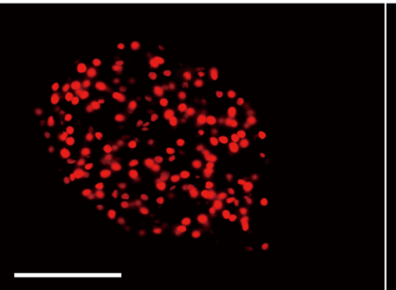

mCherry

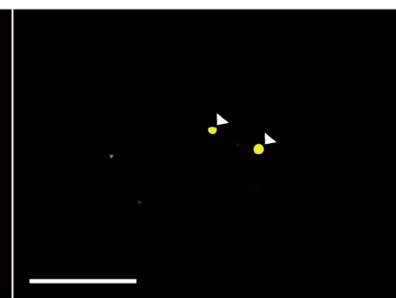

mVenus

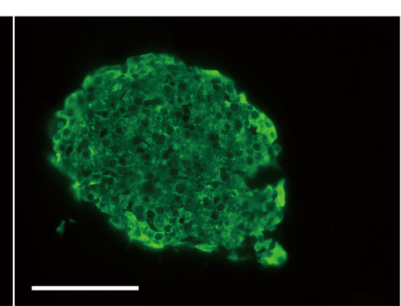

Insulin

B

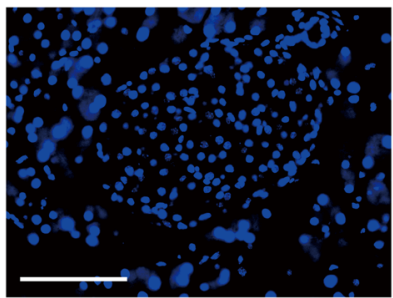

DAPI

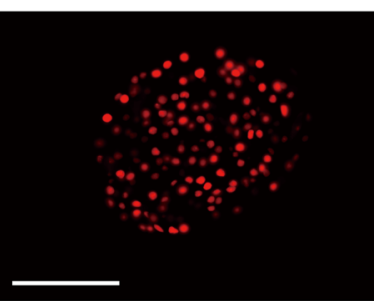

mCherry

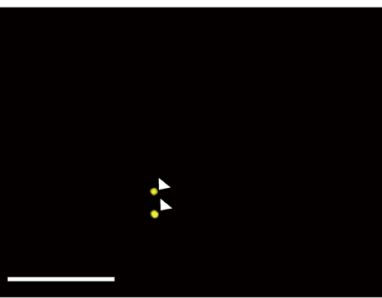

mVenus

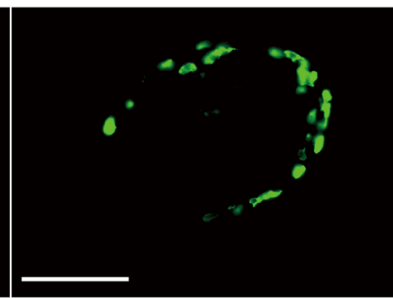

Glucagon

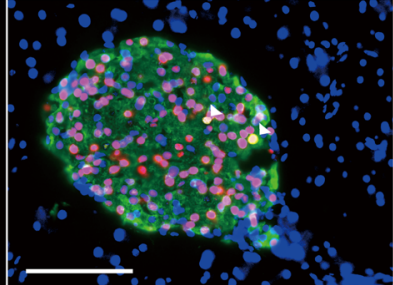

Overlay

C

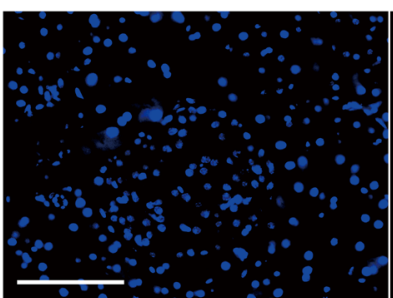

DAPI

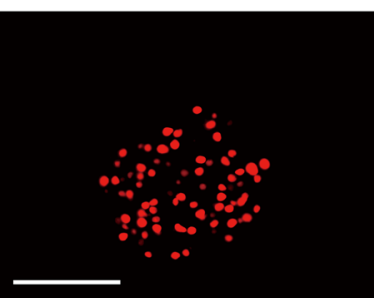

mCherry

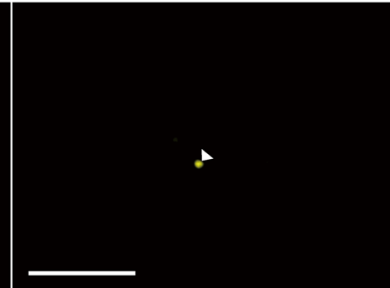

mVenus

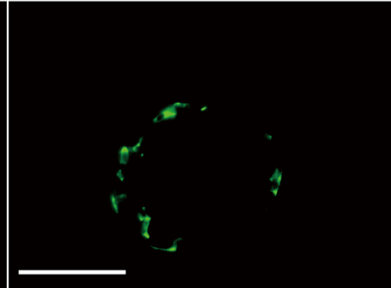

Somatostatin

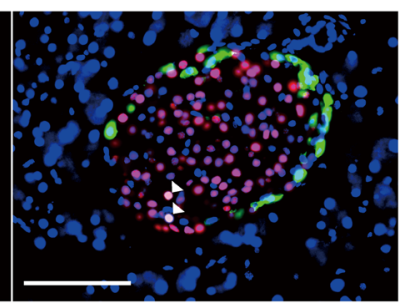

Overlay

D

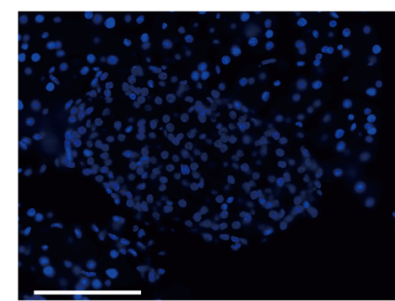

DAPI

E

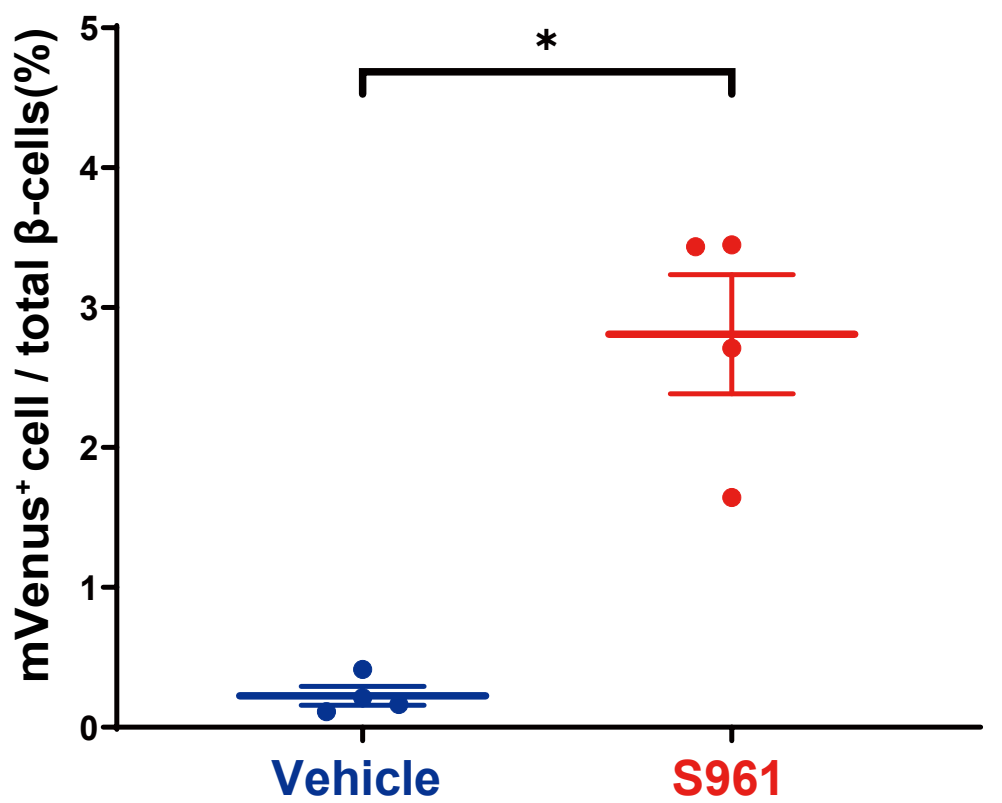

F

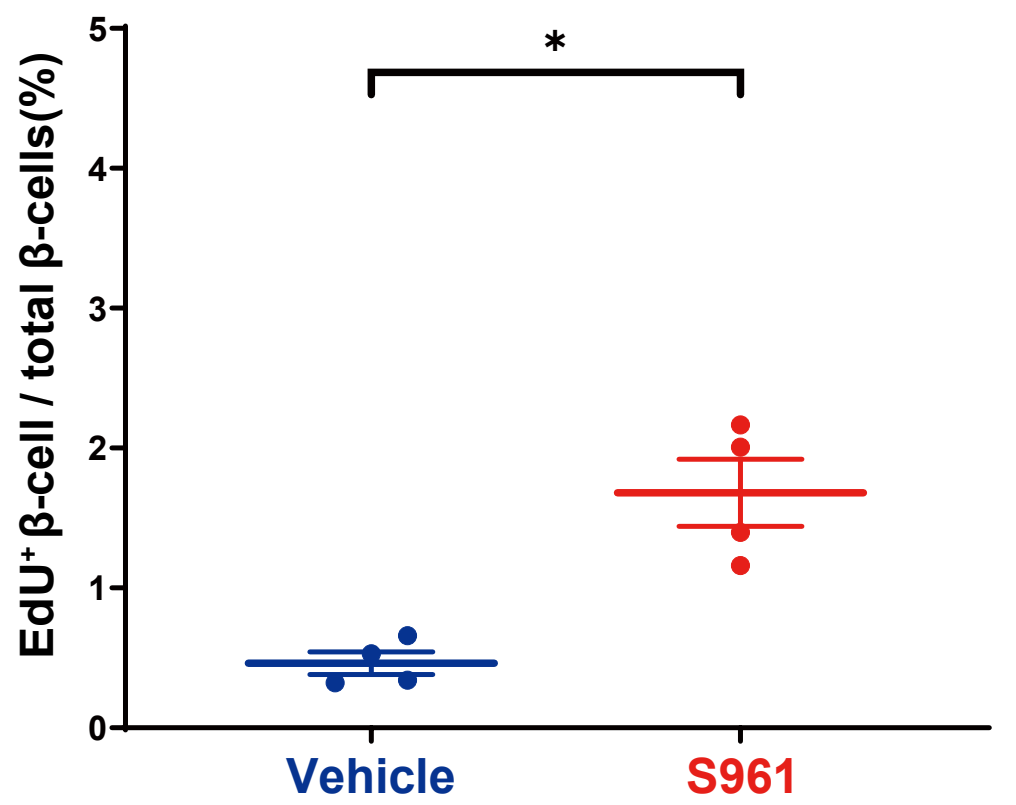


Figure 4 Rxiv preprint doi: https://doi.org/10.1101/65p904; t/

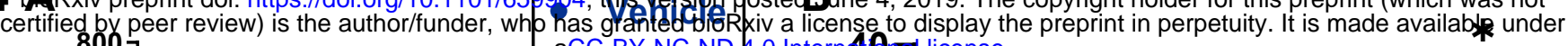

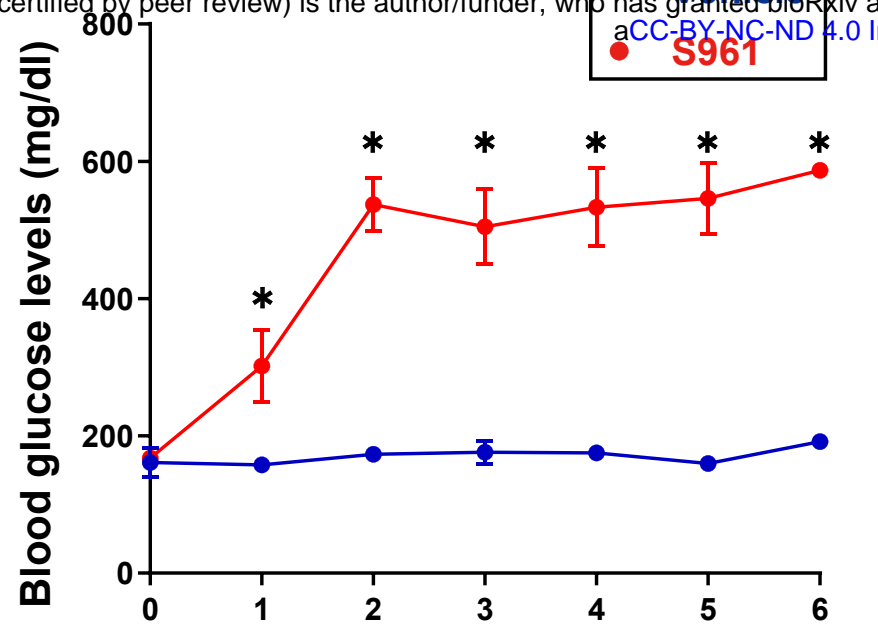

C
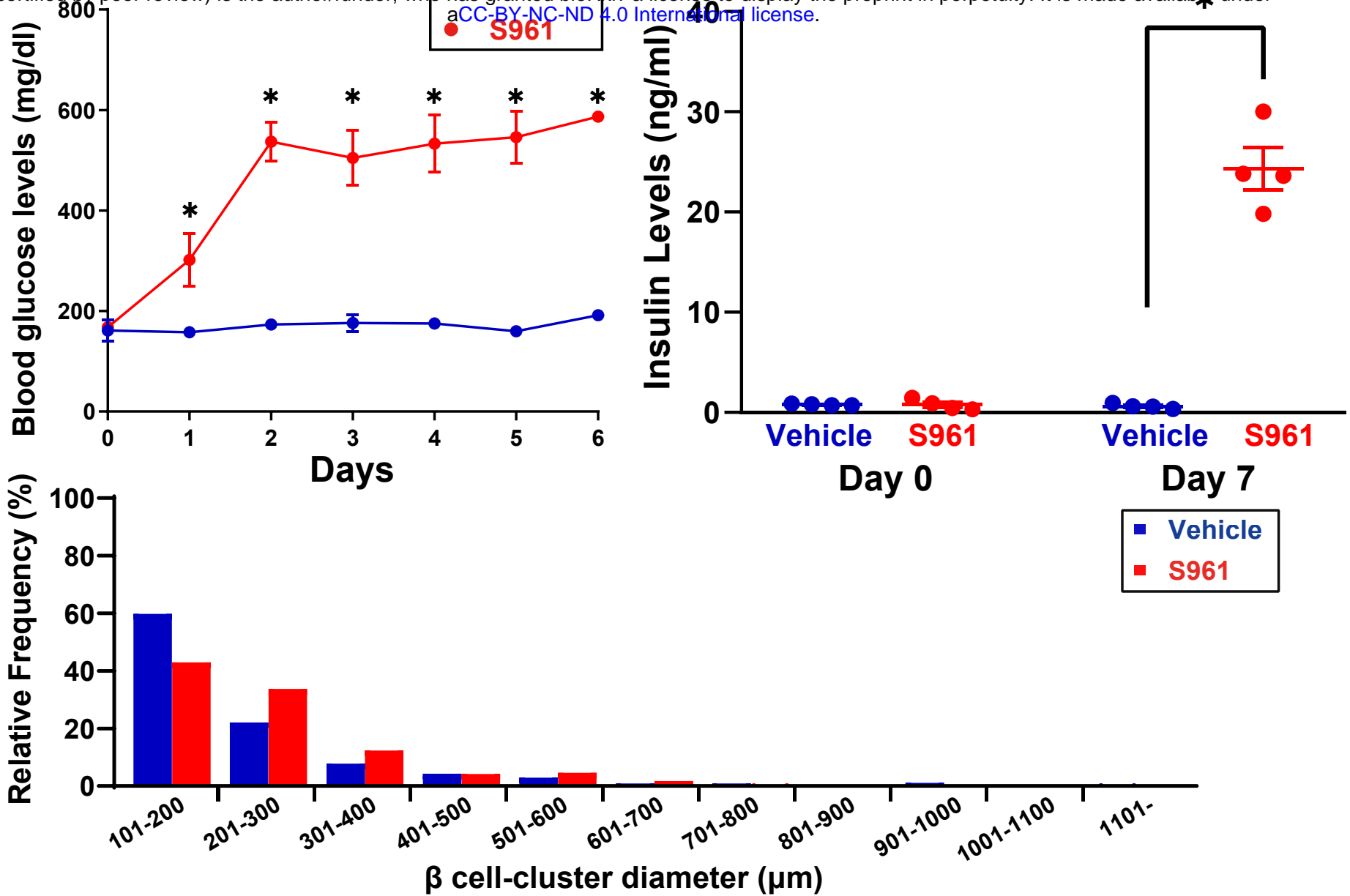

D

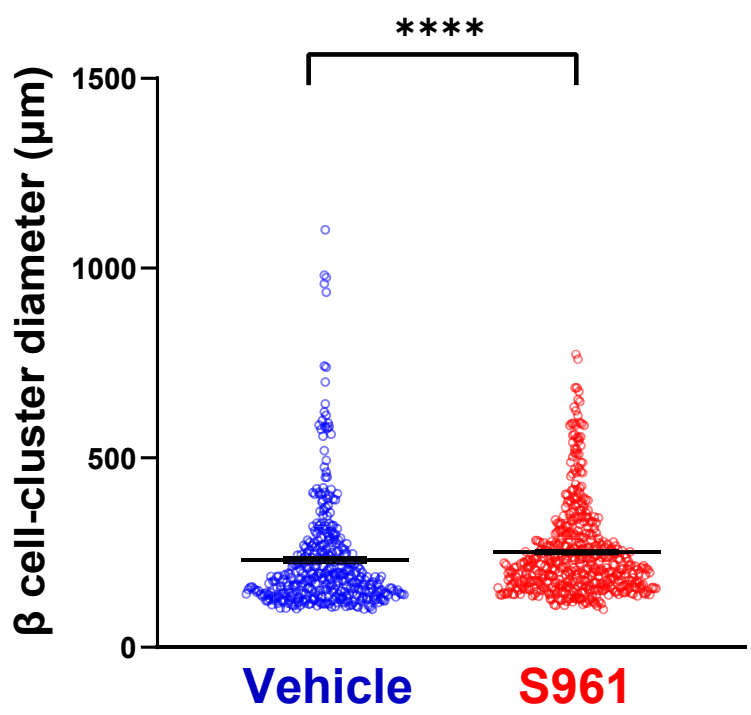

F

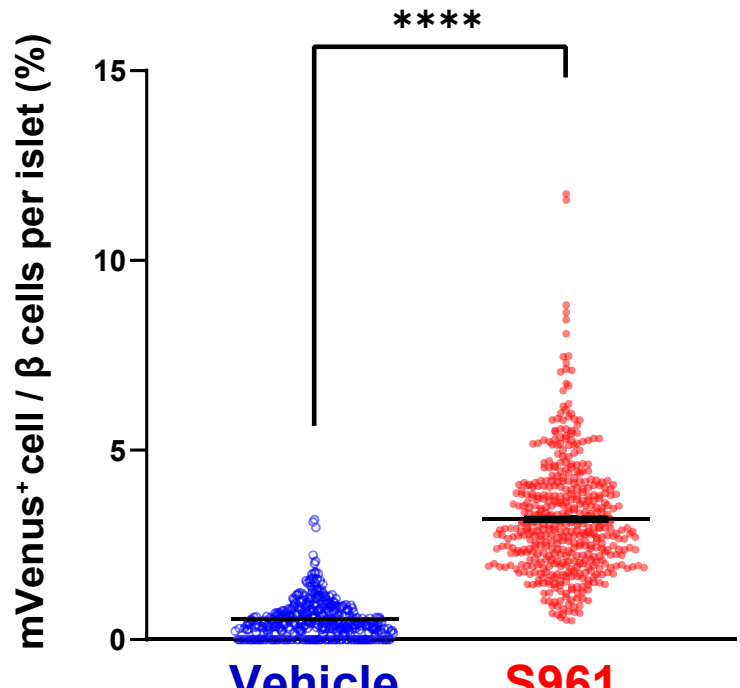

E

G
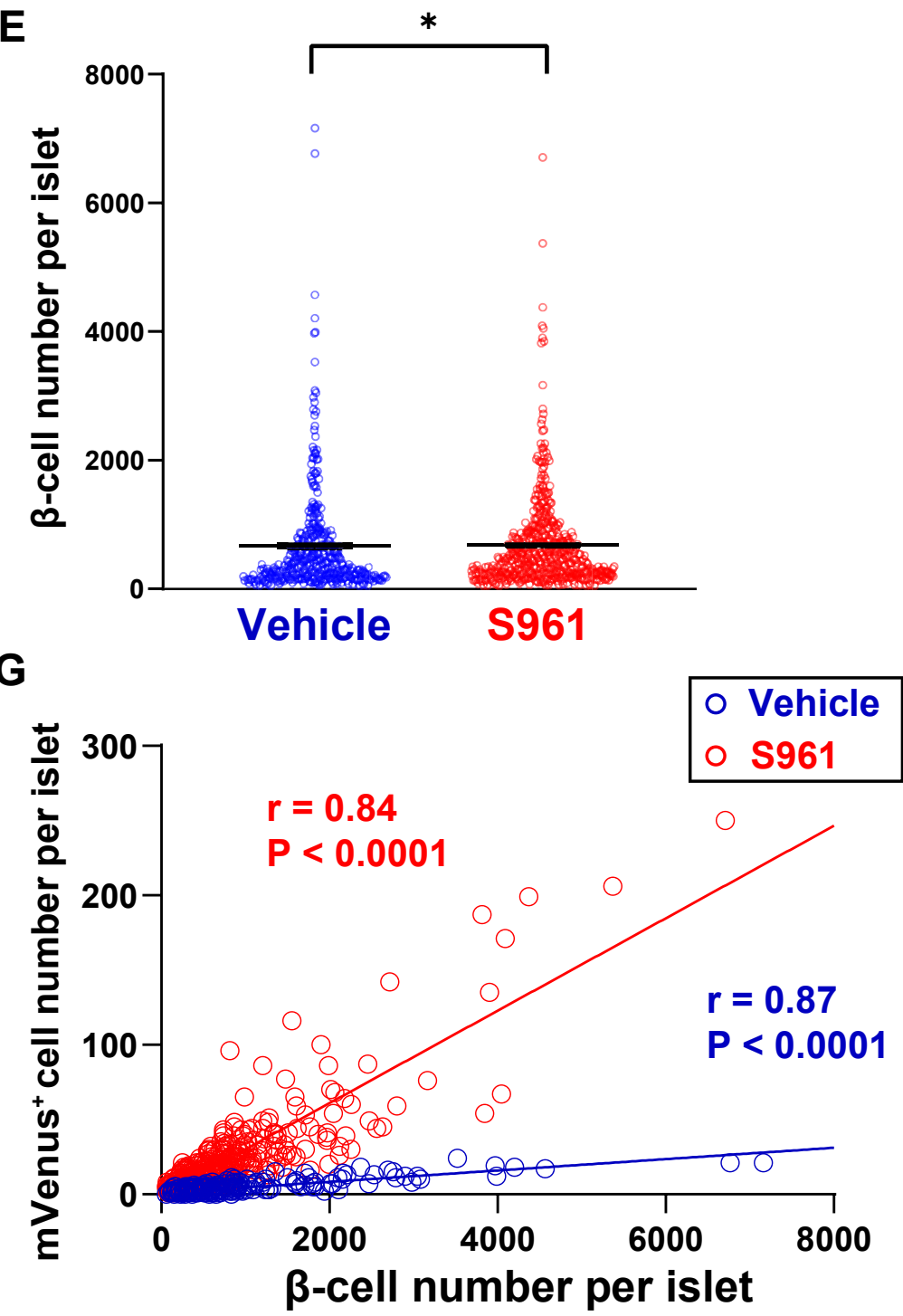
Fiqure 5 bioRxiv preprint doi: https://doi.org/10.1101/659904; this version posted June 4, 2019. The copyright holder for this preprint (which was not

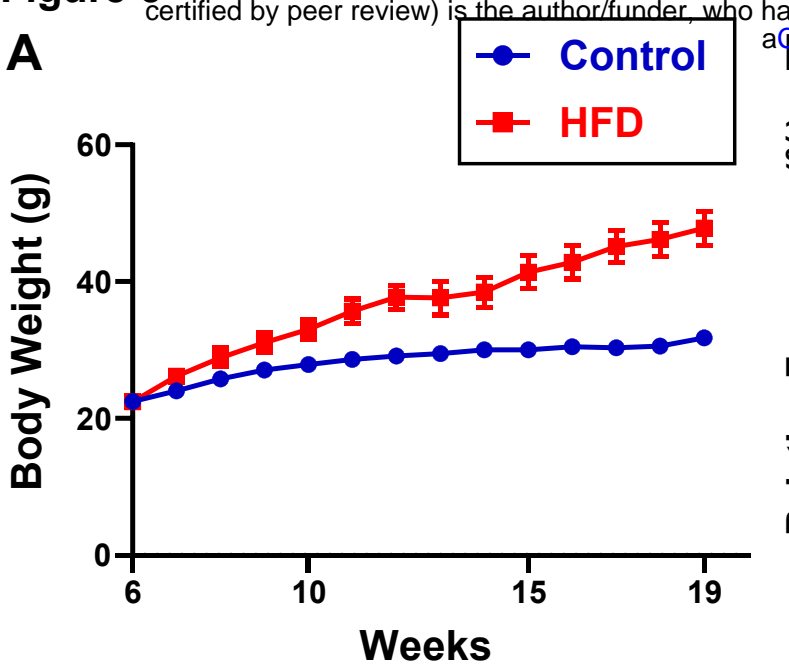

C
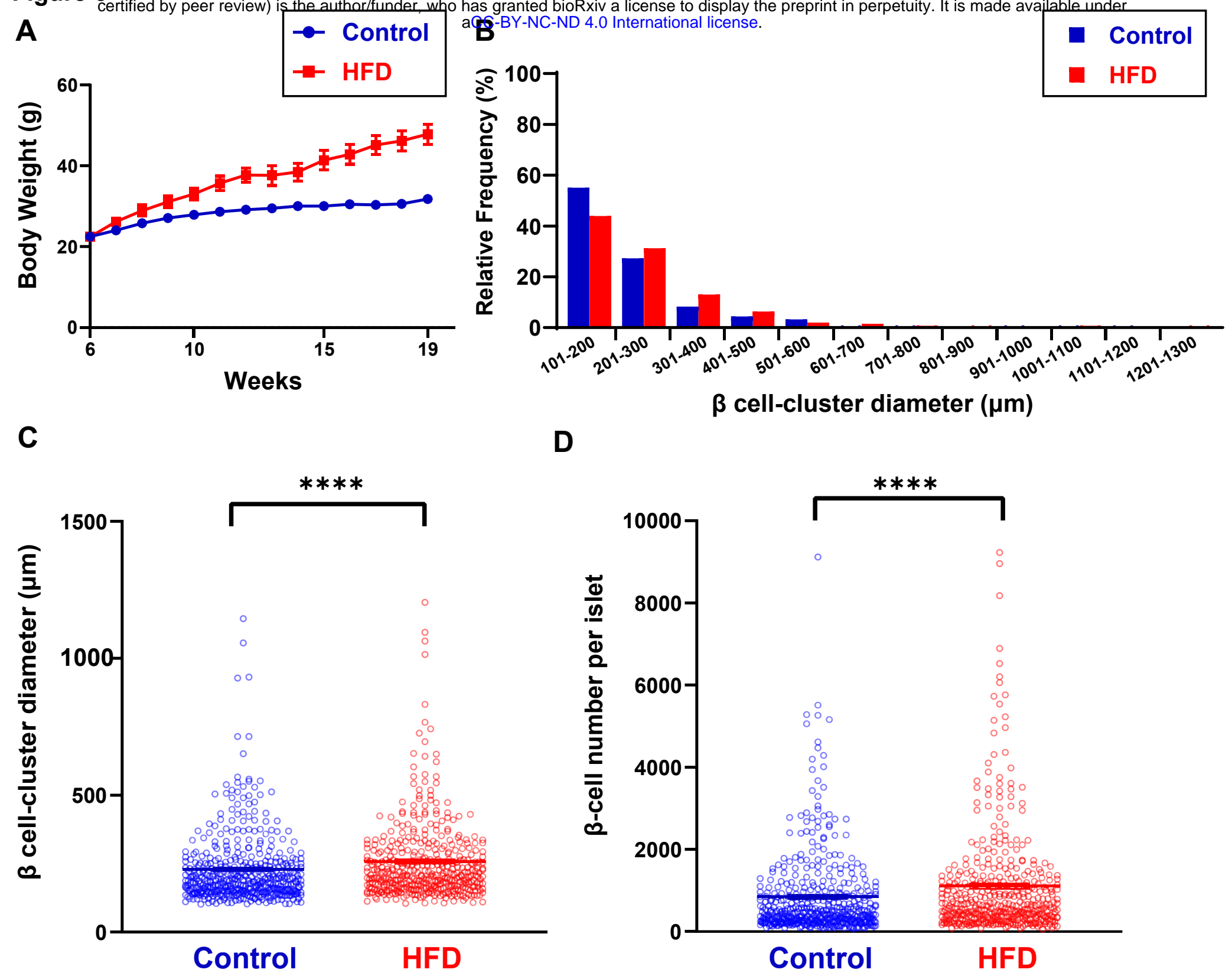

E

F
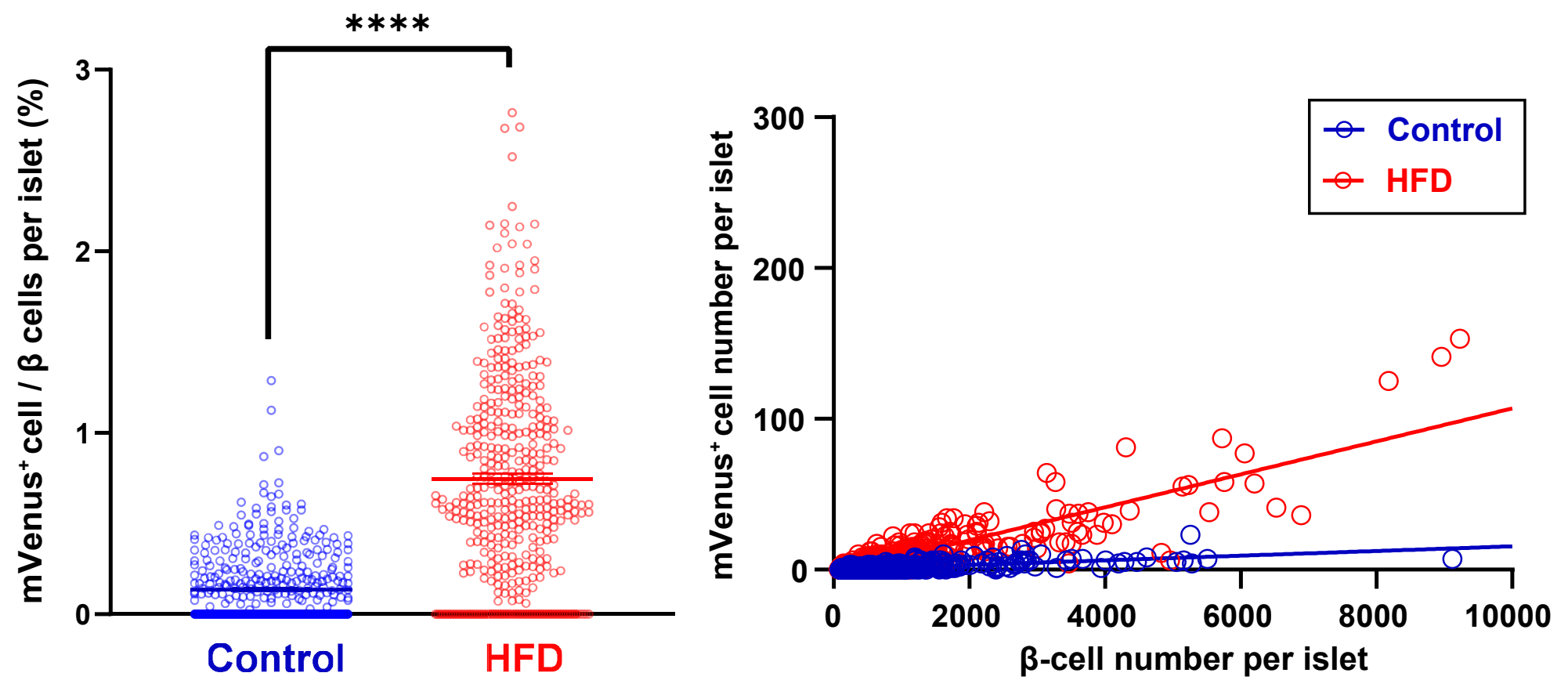
Figure 6 bioRxiv preprint doi: https://doi.org/10.1101/659904; this version posted June 42019 . The copyright holder for this preprint (which was not

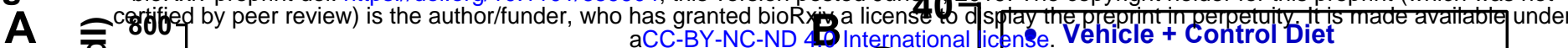
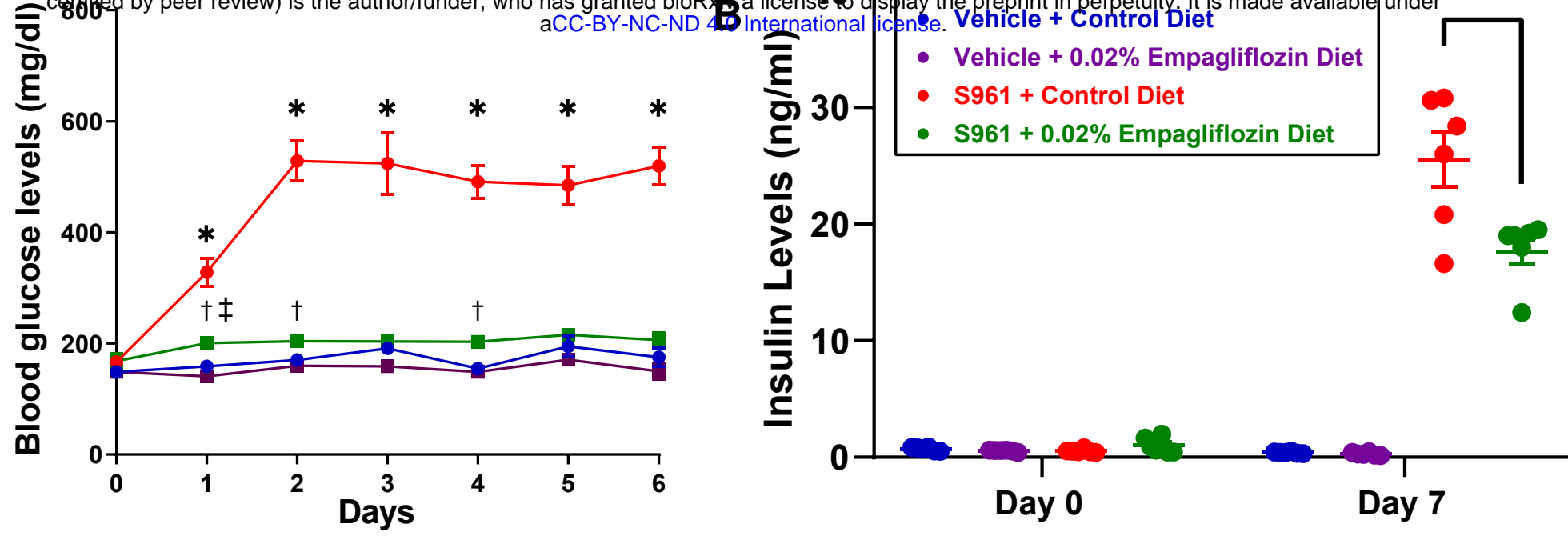

C

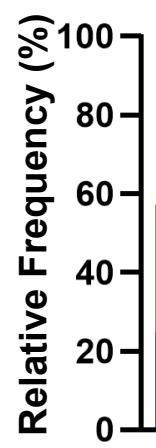

101.20

D

E

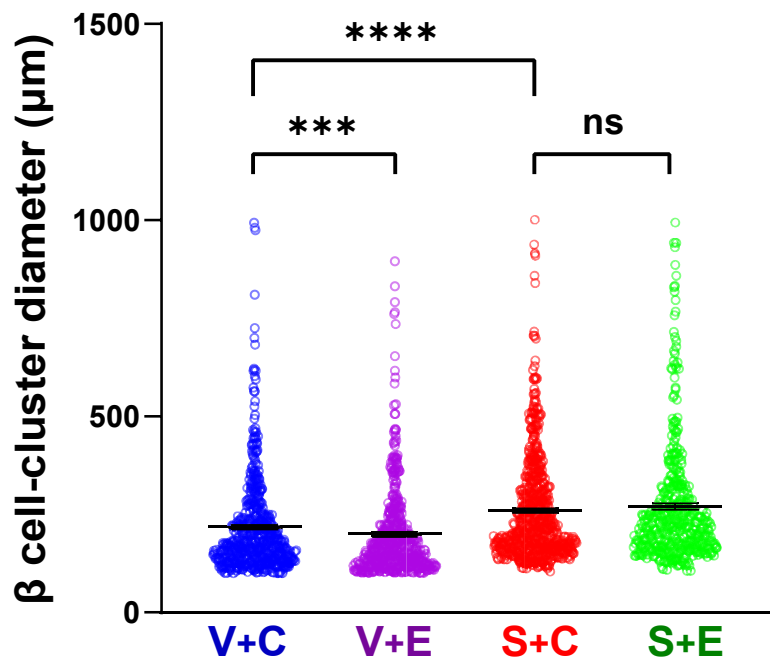

$\mathbf{F}$

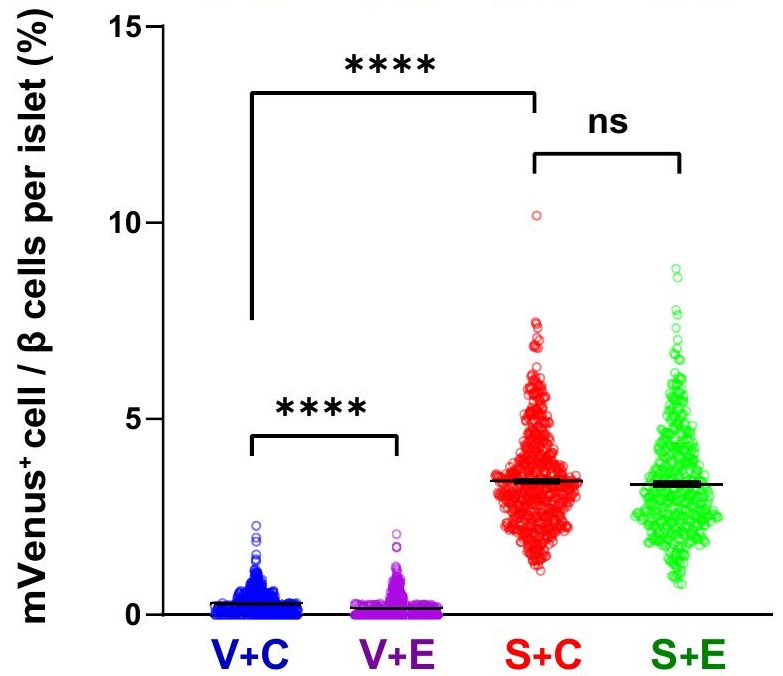

$\mathbf{G}$
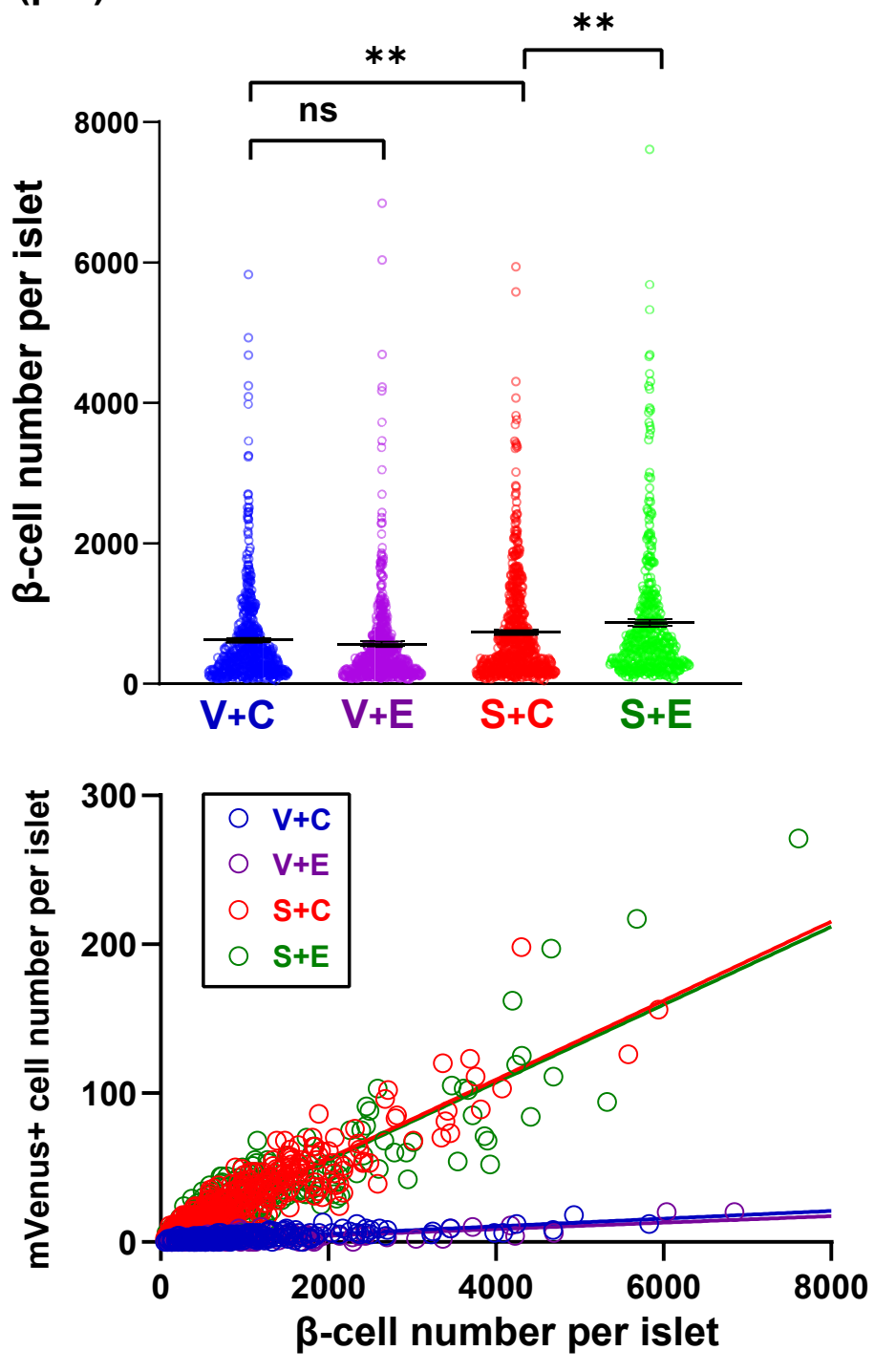

- Vehicle + Control Diet

- Vehicle $+0.02 \%$ Empagliflozin Diet

- $\$ 961+$ Control Diet

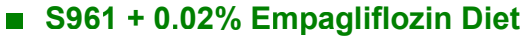

\section{$\beta$ cell-cluster diameter $(\mu \mathrm{m})$}

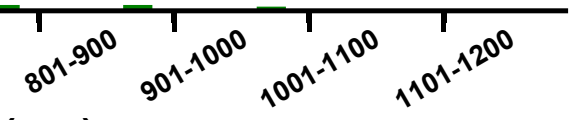

